Document downloaded from:

http://hdl.handle.net/10251/97907

This paper must be cited as:

Pretel-Jolis, R.; Moñino Amoros, P.; Robles Martínez, A.; Ruano García, MV.; Seco Torrecillas, A.; Ferrer, J. (2016). Economic and environmental sustainability of an AnMBR treating urban wastewater and organic fraction of municipal solid waste. Journal of Environmental Management. 179:83-92. doi:10.1016/j.jenvman.2016.04.057

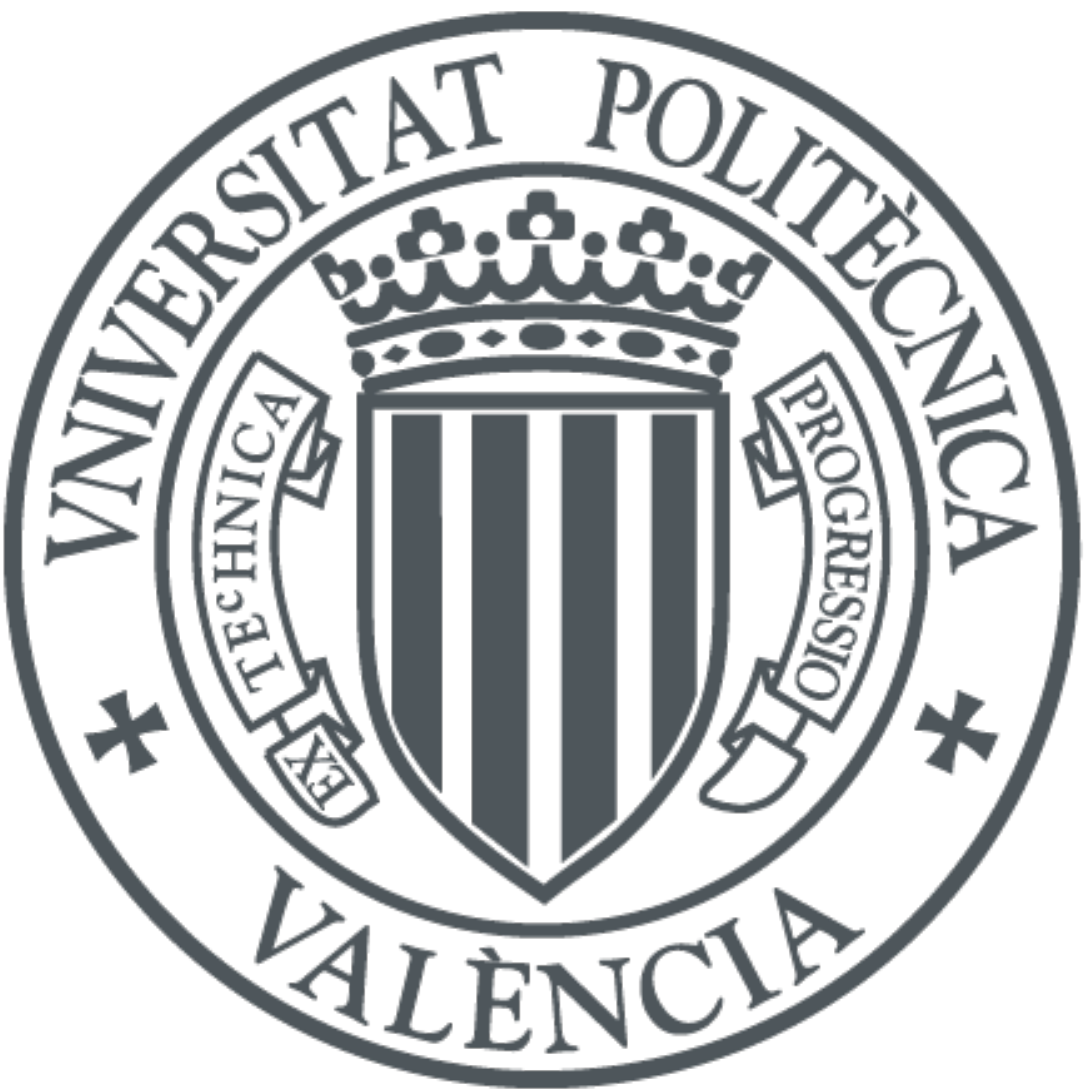

The final publication is available at

http://dx.doi.org/10.1016/j.jenvman.2016.04.057

Copyright Elsevier

Additional Information 


\title{
Economic and environmental sustainability of an AnMBR treating urban wastewater and organic fraction of municipal solid waste
}

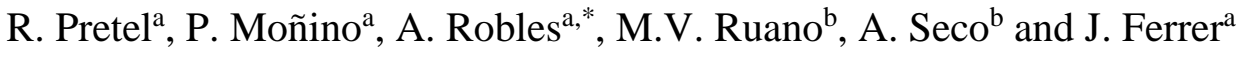 \\ a Institut Universitari d'Investigació d'Enginyeria de l'Aigua i Medi Ambient, IIAMA, Universitat \\ Politècnica de València, Camí de Vera s/n, 46022 Valencia, Spain (e-mail: rutprejo@upv.es; \\ patmoiam@upv.es; ngerobma@upv.es; jferrer@hma.upv.es) \\ b Departament d'Enginyeria Química, Escola Tècnica Superior d'Enginyeria, Universitat de València, \\ Avinguda de la Universitat s/n, 46100 Burjassot, Valencia, Spain (e-mail: \\ m.victoria.ruano@uv.es; aurora.seco@uv.es) \\ * Corresponding author: tel. +34 9638799 61, fax +34 9638790 09, e-mail: ngerobma@upv.es
}

\begin{abstract}
The objective of this study was to evaluate the economic and environmental sustainability of a submerged anaerobic membrane bioreactor (AnMBR) treating urban wastewater (UWW) and organic fraction of municipal solid waste (OFMSW) at ambient temperature in mild/hot climates. To this aim, power requirements, energy recovery from methane (biogas methane and methane dissolved in the effluent), consumption of reagents for membrane cleaning, and sludge handling (polyelectrolyte and energy consumption) and disposal (farmland, landfilling and incineration) were evaluated within different operating scenarios. Results showed that, for the operating conditions considered in this study, AnMBR technology is likely to be a net energy producer, resulting in considerable cost savings (up to €0.023 per $\mathrm{m}^{3}$ of treated water) when treating low-sulphate influent. Life cycle analysis (LCA) results revealed that operating at high sludge retention times (70 days) and treating UWW jointly with OFMSW enhances the overall environmental performance of AnMBR technology.
\end{abstract}

\section{Keywords}


Anaerobic membrane bioreactor (AnMBR); ambient temperature; energy consumption; life cycle analysis (LCA); organic fraction of municipal solid waste (OFMSW); urban wastewater (UWW).

\section{Introduction}

Nowadays, electricity consumption is a key element in the life cycle analysis (LCA) of a wastewater treatment plant (WWTP), mainly due to its environmental impact through global warming potential (GWP) (Garrido-Baserba et al., 2013; Corominas et al., 2013). In this respect, there has been increased interest during the last years in studying the feasibility of using submerged anaerobic MBRs (AnMBRs) to treat urban wastewater (UWW) (Fenu et al., 2010, Lin et al., 2013, Ozgun et al., 2013). This interest focuses on the greater sustainability of anaerobic rather than aerobic processes: lower sludge production; lower energy consumption since oxygen is not required for organic matter removal; and recovery of energy through methane production (Giménez et al., 2011; Robles et al., 2012; Raskin, 2012; Smith et al., 2013). On the other hand, the food industry produces considerable amounts of lipid-rich waste in slaughterhouses and in the processing of edible oils, dairy products and olive oil (Ramos et al., 2014). Therefore, treating the organic fraction of municipal solid waste (OFMSW) jointly with UWW in an AnMBR system may represent a great sustainable option due to the following: 1) increasing biogas production since more organic matter is entering the system; 2) reducing fossil fuel consumption related to OFMSW transportation, since it can be collected together with the grey water from kitchens; and 3) avoiding environmental issues (contamination of soil, water and air) that may occur when OFMSW is landfilled. Moreover, Cirne at al. (2007) stated that lipids are attractive substrates in anaerobic digestion and co-digestion processes due to their high theoretical methane yield when compared to proteins or carbohydrates. 
Despite its advantages, several issues have been recognised elsewhere as potential drawbacks which may affect the sustainability of AnMBR technology. One key issue is the competition between Methanogenic Archaea (MA) and Sulphate Reducing Bacteria (SRB) for the available substrate (Hulshoff Pol, 1998) when there is significant sulphate content in the influent, reducing therefore the available COD for methanisation. For UWW, which can easily present low $\mathrm{COD} / \mathrm{SO}_{4}-\mathrm{S}$ ratios, this competition can critically affect the amount and quality of the biogas produced. Specifically, $2 \mathrm{~kg}$ of COD are consumed by SRB in order to reduce $1 \mathrm{~kg}$ of influent $\mathrm{SO}_{4}-\mathrm{S}$ (see, for instance, Giménez et al., 2011; Pretel et al., 2014). Therefore, higher biogas productions would be achieved when there is little sulphate content in the influent. Another key issue is membrane fouling and cleaning, which can be significantly important in anaerobic digesters treating lipid-rich wastes (He et al., 2005, Ramos et al. 2014; Dereli et al., 2014). Membrane fouling is the result of the interaction between membrane surface and sludge suspension (Lin et al., 2011), affecting system performance in terms of economic viability and effluent quality. In this respect, membrane fouling and cleaning issues remain a critical obstacle limiting the widespread application of membrane systems in wastewater treatment (Jeison, 2007; Judd, 2011; Stuckey, 2012; Lin et al., 2013). Hence, both physical and chemical cleaning technics should be considered for fouling mitigation, maintaining efficient membrane performance and therefore the well balanced behaviour of the whole system.

The objective of this study was to evaluate the LCA of an AnMBR system treating UWW and OFMSW at ambient temperature in mild/hot climates. To this aim, power requirements, energy recovery from methane (biogas methane and methane dissolved in 
the effluent), consumption of reagents for membrane cleaning and sludge handling (polyelectrolyte and energy consumption) and disposal (farmland, landfilling and incineration) were evaluated within different operating scenarios.

\section{Materials and methods}

\subsection{AnMBR plant description}

An AnMBR pilot plant was continuously operated using the effluent of a full-scale WWTP pre-treatment jointly with food waste collected from university canteens. The food waste was grounded into small particles through an experimental set-up simulating a household food waste grinding system. The average AnMBR influent characteristics are shown in Table 1 . This influent was characterised by a COD/SO $4-\mathrm{S}$ ratio from approx. 5.5 to $9.5 \mathrm{~kg} \mathrm{COD} \cdot \mathrm{kg}^{-1} \mathrm{SO}_{4}-\mathrm{S}$.

The AnMBR plant consists of an anaerobic reactor with a working volume of about 0.9 $\mathrm{m}^{3}$ connected to two membrane tanks (MT1 and MT2) each one with a working volume of $0.6 \mathrm{~m}^{3}$, giving a system total working volume of $2.1 \mathrm{~m}^{3}$. Each membrane tank includes one ultrafiltration hollow-fibre membrane commercial system (PURON ${ }^{\circledR}$, Koch Membrane Systems, $0.05 \mu \mathrm{m}$ pore size, $31 \mathrm{~m}^{2}$ total filtering area). The filtration process was studied from experimental data obtained from MT1 (operated recycling continuously the obtained permeate to the system), whilst the biological process was studied using experimental data obtained from MT2 (operated for controlling the hydraulic retention time (HRT) without recycling the obtained permeate). Hence, different $20^{\circ} \mathrm{C}$-standardised transmembrane fluxes $\left(\mathrm{J}_{20}\right)$ were tested in MT1, without affecting HRT. For the introduction of OFMSW to the AnMBR, a rotofilter of 0.5-mm 
screen-size was installed. A $0.2-\mathrm{m}^{3}$ tank for OFMSW equipped with a stirrer for homogenisation of the sample and membrane diffusers for aeration and removal of fats and oils was also included in the plant. Further details on this AnMBR can be found in Robles et al. (2015) and Moñino et al. (2016).

\subsection{AnMBR operating conditions}

The AnMBR plant was operated for 536 days within a wide range of operating conditions regarding both biological and filtration processes. Five operating scenarios were selected to conduct the LCA of the AnMBR system, extracted from Moñino et al. (2016). Specifically, this study comprised two different operating periods. Firstly, the AnMBR performance was evaluated when only UWW was fed to the plant (Scenarios 1 and 2). Then, the system performance was evaluated when feeding also the OFMSW (Scenarios 3, 4 and 5).

\subsubsection{Biological process}

Variations in sludge retention time (SRT) and penetration factor (PF, defined as the percentage of population having a kitchen disposer) were studied to account for the dynamics in methane and sludge productions over time. During the 536-day experimental period, the plant was operated at SRT of 40 and 70 days, whilst PF was set to 0,40 and $80 \%$ (varying therefore the $\mathrm{COD} / \mathrm{SO}_{4}-\mathrm{S}$ ratio in the influent). The results obtained in this study correspond with results obtained in an AnMBR system operated at ambient temperature in mild/hot climates $\left(25-30^{\circ} \mathrm{C}\right)$. Methane and sludge productions were compared among the different scenarios. It must be said that a dissolved methane 
capture efficiency of $80 \%$ was considered in this study (the remaining $20 \%$ was considered to be discharged in the effluent (10\%) and emitted to the atmosphere (10\%)).

As commented before, five different experimental scenarios related to biological process were considered to evaluate the economic and environmental sustainability of the AnMBR plant when treating high-sulphate influent (around 98-115 $\mathrm{mg} \mathrm{SO} \mathrm{SO}_{4} \mathrm{~S} \cdot \mathrm{L}^{-1}$ ). Table 2 shows the average of the main operating conditions and the resulting performance indexes regarding the biological process throughout the selected scenarios. Further details as regards the performance of the biological process in the AnMBR can be found in Moñino et al. (2016).

\section{Influent sulphate concentration}

The effect of the influent sulphate on the economic and environmental sustainability of the AnMBR was also evaluated. As mentioned before, the UWW and OFMSW fed to the AnMBR plant was characterised by low $\mathrm{COD} / \mathrm{SO}_{4}-\mathrm{S}$ ratios (from approx. 5.5 to 9.5 $\left.\mathrm{kg} \mathrm{COD} \cdot \mathrm{kg}^{-1} \mathrm{SO}_{4}-\mathrm{S}\right)$. Therefore, an important fraction of the influent COD was consumed by SRB (from about 36 to $20 \%$ of the influent COD). To be precise, the sulphate content in the influent ranged from 98 to $115 \mathrm{mg} \mathrm{SO}{ }_{4}-\mathrm{S} \cdot \mathrm{L}^{-1}$, from which approx. $98 \%$ was reduced to sulphide. Therefore, about $192-225 \mathrm{mg} \cdot \mathrm{L}^{-1}$ of influent COD were consumed by SRB, reducing the amount of methane produced in the pilot plant (i.e. methane was not fully efficiently produced). Specifically, methane production was reduced around $67-79 \mathrm{~L} \cdot \mathrm{m}^{-3}$ due to the performance of SRB. 
The results obtained in this study were compared to the theoretical results obtained in an AnMBR system treating medium- and low-sulphate UWW and OFMSW (50 and 10\% of the original $\mathrm{SO}_{4}-\mathrm{S} \cdot \mathrm{L}^{-1}$ content in the influent). To this aim, the methane production when treating medium- and low-sulphate influent was calculated on the basis of the theoretical methane yield under standard temperature and pressure conditions: 350 $\mathrm{L}_{\mathrm{CH} 4} \cdot \mathrm{kg}^{-1} \mathrm{COD}$.

\subsubsection{Filtration process}

Table 3 illustrates the average of the main operating conditions regarding the filtration process for the different scenarios considered. The gas sparging intensity for membrane scouring (measured as specific gas demand per square metre of membrane area, $\mathrm{SGD}_{\mathrm{m}}$ ) was set to $0.10 \mathrm{~m}^{3} \cdot \mathrm{h}^{-1} \cdot \mathrm{m}^{-2}$ on the basis of previous experimental results (Pretel et al., 2016a). The $20^{\circ} \mathrm{C}$-standardised transmembrane flux $\left(\mathrm{J}_{20}\right)$ was established for meeting critical filtration conditions depending on the mixed liquor suspended solids concentration reached in the anaerobic reactor $\left(\mathrm{MLSS}_{\mathrm{AnR}}\right)$. On the basis of previous results (see, for instance, Pretel et al., 2016a), operating at critical filtration conditions resulted in minimum filtration costs. The average transmembrane pressure (TMP) during filtration was 0.10 bars; the sludge recycling flow in anaerobic reactor and membrane tank $\left(\mathrm{SRF}_{\mathrm{AnR}}\right.$ and $\mathrm{SRF}_{\mathrm{MT}}$ respectively) was set to 2.7 and $1.0 \mathrm{~m}^{3} \cdot \mathrm{h}^{-1}$, respectively; and the biogas recycling flow to the anaerobic reactor $\left(\mathrm{BRF}_{\mathrm{AnR}}\right)$ was established in $1.5 \mathrm{~m}^{3} \cdot \mathrm{h}^{-1}$ (see Table 3$)$.

It is worth to point out that no meaningful differences were observed in membrane fouling rate when feeding UWW in comparison with treating UWW jointly with 
OFMSW. However, further research is required to accurately determine the effect of treating UWW jointly with OFMSW on membrane fouling rate. As commented before, some authors in previous studies (see for instance He et al., 2005, Ramos et al., 2014; Dereli et al., 2014) have detected an increase in membrane fouling and cleaning issues in anaerobic digesters treating lipid-rich wastes. Hence, the results obtained in this study were compared to the theoretical results obtained considering that membrane fouling when treating UWW jointly with OFMSW is 150 and $200 \%$ of the fouling rate resulting from treating UWW. This increase in membrane fouling directly affects membrane cleaning frequency.

In this study, five membrane operating stages were considered in the membrane operating mode as the following: filtration, relaxation and back-flushing, degasification and ventilation. Concerning membrane physical cleaning, the downtime for membrane physical cleaning through back-flushing and relaxation was set to $1.3 \%$ and $16 \%$ of the membrane operating time, respectively.

As regards to membrane chemical cleaning, according to Judd and Judd (2011) and previous experiments (see, for instance, Robles et al. (2012)), 9.5 months can be set as the interval for membrane cleaning with chemicals when operating under critical filtration conditions (operating at $J_{20}=J_{C 20}$ ). When fouling rate was $150 \%$ (Scenario 3, 4 and 5) and $200 \%$ (Scenario 5) of the experimentally-observed fouling rate, an interval for membrane cleaning of 6.3 and 4.8 moths were theoretically estimated. Sodium hypochlorite $(\mathrm{NaOCl})$ and citric acid were the two reagents required for cleaning the membranes chemically. 


\subsection{Analytical monitoring}

The following parameters were analysed in mixed liquor, influent, and effluent streams according to Standard Methods (2005): total solids (TS); total suspended solids (TSS); volatile suspended solids (VSS); sulphate $\left(\mathrm{SO}_{4}-\mathrm{S}\right)$; nutrients (ammonium $\left(\mathrm{NH}_{4}-\mathrm{N}\right)$ and orthophosphate $\left.\left(\mathrm{PO}_{4}-\mathrm{P}\right)\right)$; and chemical oxygen demand (COD). The methane fraction of the biogas was measured experimentally using a gas chromatograph equipped with a Flame Ionization Detector (GC-FID, Thermo Scientific) in accordance with Giménez et al. (2011). Biogas sparging for membrane scouring and mixing avoided super-saturation of gasses in the liquid phase and guaranteed the minimum concentration of dissolved methane in the effluent, i.e. equilibrium conditions were reached (Giménez et al., 2012). Therefore, the distribution obtained between gas and liquid phase of the produced methane corresponded to the saturation methane concentration given by Henry's Law (Giménez et al., 2012).

\subsection{Energy balance description}

The energy balance of the AnMBR system consisted of: power requirements and energy recovery from both biogas methane and methane dissolved in the effluent. The heat energy term was assumed negligible since the process was evaluated at ambient temperature conditions.

The equipment considered for calculating power requirements consisted of the following: rotofilter; equalisation tank stirrer; anaerobic reactor feeding pump; membrane tank sludge feeding pump; anaerobic reactor sludge mixing pump; anaerobic 
reactor biogas recycling blower (for stirring the anaerobic reactor); membrane tank biogas recycling blower (biogas sparging); permeate pump; and dewatering system (centrifuges). The total cost of the technologies needed for energy recovery (degassing membrane for dissolved methane capture and microturbine-based CHP for energy generation) were also considered. The power requirements for each of the scenarios evaluated in this study were calculated using the simulation software DESASS (Ferrer et al., 2008), which includes a general tool that enables calculating the energy consumption of the different units comprising a WWTP (Pretel et al., 2016b).

\subsection{Operating cost assessment}

The operating cost analysis conducted in this study included: energy consumption, consumption of reagents for membrane cleaning, and sludge handling (polyelectrolyte and energy consumption) and disposal (farmland, landfilling and incineration). The energy term was set to $€ 0.138$ per $\mathrm{kWh}$ according to the electricity rates and prices in Spain (2013).

The selected technology when calculating the capture of the methane dissolved in the effluent was degassing membranes. The degassing membrane considered in this study (DIC Corporation EF-120 Large-scale Degassing Module) consisted in a hollow-fibre membrane module made of PMP (polyolefin). The membrane was assumed to operate at vacuum pressure drop of $60 \mathrm{kPa}$ with a flow rate of $30 \mathrm{~m}^{3} \cdot \mathrm{h}^{-1}$. The capital cost of the membrane was approx. $€ 45$ per $\mathrm{m}^{2}$. 
Concerning membrane chemical cleaning, the sodium hypochlorite and citric acid cost assumed in this study was $€ 11$ per $\mathrm{L}$ and $€ 23.6$ per $\mathrm{kg}$ (Didaciencia S.A.), respectively.

Concerning sludge handling and disposal, centrifuges require the use of polyelectrolyte for proper sludge conditioning. The dose of polyelectrolyte considered in our study was $6 \mathrm{~kg} \cdot \mathrm{t}^{-1}$ TSS (Sainz- Lastre, 2005), and the assumed polyelectrolyte cost was $€ 2.52$ per kg Polyelectrolyte (Miliarium Aureum, 2013). The fate of the wasted sludge was established as follows: $80 \%$ to be used as fertiliser on farmland, $10 \%$ to incineration, and $10 \%$ to landfilling (MAGRAMA, 2015). The considered cost for farmland, incineration and landfilling was $€ 4.8,250.0$ and 30.1 per $\mathrm{t}$ TSS, respectively (Miliarium Aureum, 2013).

Further details on OPEX calculations, as well as the unit cost values used in this study, can be found in Pretel et al. (2016c).

\subsection{LCA implementation}

The implementation of the LCA framework was conducted in accordance with UNE-EN ISO 14040 (ISO, 2006). The life cycle inventories (LCI) of individual materials and processes were compiled using the Ecoinvent Database v.3 accessed via SimaPro 8.02 (PRé Consultants; The Netherlands). The Centre of Environmental Science (CML) 2 baseline 2000 methodology was used to conduct the impact assessment. The impact categories considered in this study were: GWP with a 100-year time horizon $\left(\mathrm{GWP}_{100}\right.$; quantified as $\mathrm{kg} \mathrm{CO}_{2}$ eq.); abiotic depletion (quantified as $\mathrm{kg} \mathrm{Sb}$ eq.); marine aquatic 
ecotoxicity (quantified as $\mathrm{kg}$ 1,4-DB eq.); acidification (quantified as $\mathrm{kg} \mathrm{SO}_{4}$ eq.); and eutrophication (quantified as $\mathrm{kg} \mathrm{PO}_{4}$ eq.).

Five main factors were considered when determining the environmental performance of the evaluated AnMBR system: (1) power requirements; (2) energy recovery from methane (biogas and methane dissolved in the effluent); (3) consumption of reagents for membrane cleaning (sodium hypochlorite and citric acid); (4) sludge handling (polyelectrolyte and energy consumption) and disposal (farmland, landfilling and incineration); and (5) final effluent discharge, considering fertigation (i.e. irrigation with nutrient-rich water)

As commented before, energy offsets through on-site production were calculated assuming the capture of both biogas methane and dissolved methane in the effluent. Moreover, high-, medium- and low-sulphate AnMBR influent were considered in order to calculate the corresponding energy recovery from methane production.

Calculations of fertiliser offsets from both farmland and fertigation included assumptions of nitrogen and phosphorus bioavailability (50\% and 70\%, respectively). Moreover, direct emissions to air (e.g., $\mathrm{N}_{2} \mathrm{O}, \mathrm{NH}_{3}$ ), water (e.g., $\mathrm{PO}_{4}$ ), and soil (heavy metals) were also included when sludge was applied to farmland. These calculations were consistent with other studies (Gallego et al., 2008; Rodriguez-Garcia et al., 2011; Garrido-Baserba et al., 2013; Pretel et al., 2013). 
Concerning the consumption of reagents for membrane cleaning, the effect of treating UWW jointly with OFMSW on membrane fouling (and therefore on operating costs and LCA) was assessed in this study. In particular, the effect of fouling rate on membrane cleaning frequency was evaluated. Three scenarios were established: (1) fouling rate of $100 \%$ of the experimentally-observed fouling rate (Scenario 1 and 2); (2) fouling rate of $150 \%$ of the experimentally-observed fouling rate (Scenario 3, 4 and 5); and (3) fouling rate of $200 \%$ of the experimentally-observed fouling rate (Scenario 5).

\section{Results and discussion}

As commented before, the experimental period of this study is divided into two stages, represented in Table 2 by a horizontal dashed line. The overall AnMBR performance was firstly evaluated during the operating period when feeding only UWW to the plant (Scenarios 1 and 2). After that, the overall plant performance was evaluated in the period when feeding both UWW and OFMSW (Scenarios 3, 4 and 5).

\subsection{Biological process performance}

As Table 2 shows, low methane productions were obtained during the experimental period due to the consumption of a fraction of the influent COD by SRB. As commented before, methane production was reduced around $67-79 \mathrm{~L} \cdot \mathrm{m}^{-3}$ due to the performance of SRB. Nonetheless, methane production increased significantly when operating at high SRT and treating UWW jointly with OFMSW (i.e. medium influent $\mathrm{COD} / \mathrm{SO}_{4}-\mathrm{S}$ ratios). To be precise, as shown in Table 2, methane production was 30 and $56 \mathrm{~L} \cdot \mathrm{m}^{-3}$ at PF of $0 \%$ and SRT of 40 (Scenario 1) and 70 days (Scenario 2), respectively. Nevertheless, methane production increased up to 40 (PF of $40 \%$ and 40 
days of SRT, Scenario 3), 83 (PF of $40 \%$ and 70 days of SRT, Scenario 4) and $119 \mathrm{~L} \cdot \mathrm{m}^{-}$

${ }^{3}$ (PF of $80 \%$ and 70 days of SRT, Scenario 5) by feeding UWW jointly with OFMSW.

Concerning sludge production, low/moderate amounts of wasted sludge were generated. As Table 2 shows, sludge production when only feeding UWW to the system resulted in 0.92 and $0.37 \mathrm{~kg} \mathrm{TSS} \cdot \mathrm{kg}^{-1}$ COD REMOved at SRT of 40 (Scenarios 1) and 70 days (Scenarios 2), respectively.

Nevertheless, lower wasted sludge productions were achieved when feeding UWW jointly with OFMSW: $0.47 \mathrm{~kg}$ TSS $\cdot \mathrm{kg}^{-1}$ CODREMOVED at PF of $40 \%$ and 40 days of SRT (Scenario 3), $0.27 \mathrm{~kg}$ TSS $\cdot \mathrm{kg}^{-1}$ CODREMOved at PF of $40 \%$ and SRT 70 days (scenario 4), and $0.21 \mathrm{~kg} \mathrm{TSS} \cdot \mathrm{kg}^{-1}$ CODREMOVED at PF of $80 \%$ and 70 days of SRT (Scenario 5). The lowest sludge production corresponded to Scenarios 2, 4 and 5, mainly due to operating at high SRT (70 days). On the other hand, the experimentally determined percentage of biodegradable volatile suspended solids (BVSS) resulted in values below $35 \%$ within the whole range of evaluated operating conditions, which indicated adequate stabilities of the wasted sludge. It is important to highlight that one key sustainable benefit of AnMBR technology is that the produced sludge is stabilised and no further digestion is required for its disposal on farmland. In addition, sludge production in anaerobic processes is expected to be lower than in aerobic processes.

3.2 Energy consumption and life cycle analysis results of the AnMBR system 3.2.1 Energy consumption 
Figure 1 shows the energy balance results of the AnMBR for the scenarios evaluated in this study. It is worth to point out that these scenarios were operated at nearly similar filtration conditions: i.e. near the experimentally-determined critical flux for each MLSS level evaluated. Thus, similar power requirements regarding filtration were obtained in all the scenarios. As previously commented, it is convenient to point out that the increase in membrane fouling considered when treating UWW and OFMSW results in an increase in the frequency of membrane chemical cleaning, since the filtration conditions remain similar for the scenarios evaluated. As Figure 1 shows, power requirements for membrane scouring by gas sparging accounted for the largest percentage of energy demand (about 50\%), resulting in similar values in all the evaluated scenarios.

Particularly, power requirements for membrane scouring were 0.09 and $0.07 \mathrm{kWh} \cdot \mathrm{m}^{-3}$ in Scenario 1 and 2 (operating at PF of $0 \%$ and SRT of 40 and 70 days, respectively); and $0.08,0.08$ and $0.07 \mathrm{kWh} \cdot \mathrm{m}^{-3}$ in Scenario 3, 4 and 5 (operating at SRT of 40, 70 and 70 days and PF of 40, 40 and $80 \%$, respectively).

Considering energy recovery from methane capture, the energy consumption of the system was $0.095,0.002,0.057,-0.067$ and $-0.173 \mathrm{kWh} \cdot \mathrm{m}^{-3}$ in Scenario 1, 2, 3, 4 and 5, respectively. In this respect, it is important to highlight that it was possible to increase methane production by operating at high SRT (70 days in Scenarios 2, 4 and 5) and by incorporating OFMSW to the influent (Scenarios 3, 4 and 5). Note that Scenario 2 (operating at 70 days of SRT and PF of $0 \%$ ) resulted in higher methane productions than Scenario 3 (operating at 40 days of SRT and PF of 40\%). Thus, increasing SRT from 40 to 70 days seems to have more effect in the final methane production than incorporating OFMSW to the influent from 0 to $40 \%$ of PF. On the other hand, it is 
worth to point out that AnMBR technology was likely to be a net energy producer in Scenarios 4 and 5, resulting in considerable energy offsets through on-site power energy production (up to $0.173 \mathrm{~kW}$ per $\mathrm{m}^{3}$ of treated water).

Moreover, energy savings could improve much more when treating low-sulphate UWW and OFMSW, since a low amount of COD is consumed by SRB. In this respect, a significant decrease in the AnMBR energy consumption could be achieved when treating low-sulphate influent in comparison with treating high-sulphate influent (see Figure 1). For instance, in Scenario 5, energy offsets through on-site power energy production could increase from $0.173 \mathrm{kWh} \cdot \mathrm{m}^{-3}$ to 0.269 and $0.345 \mathrm{kWh} \cdot \mathrm{m}^{-3}$ when reducing to 50 and $10 \%$ the sulphate content in the evaluated influent, respectively. Moreover, in Scenario 1, AnMBR technology may become a net energy producer since the energy consumption could be reduced from $0.095 \mathrm{kWh} \cdot \mathrm{m}^{-3}$ to 0.010 and -0.059 $\mathrm{kWh} \cdot \mathrm{m}^{-3}$ when reducing 50 and $10 \%$ the sulphate content in the evaluated influent, respectively. This highlights the great feasibility of AnMBR technology when treating wastewaters containing high $\mathrm{COD} / \mathrm{SO}_{4}-\mathrm{S}$ ratios.

It is important to note that a significant amount of heat energy would have been required to operate at mesophilic temperature conditions. For instance, increasing the operating temperature from $27^{\circ} \mathrm{C}$ (Scenario 5) to $35^{\circ} \mathrm{C}$ would have been considered unsustainable because of the considerable heat energy needed $\left(9.3 \mathrm{~kW} \cdot \mathrm{m}^{-3}\right)$.

Therefore, for the ambient temperature range of this study $\left(25-29^{\circ} \mathrm{C}\right)$, operating at high $\mathrm{PF}$ and/or high SRT and/or high $\mathrm{COD} / \mathrm{SO}_{4}-\mathrm{S}$ ratio, allows achieving significant energy savings whenever the methane generated is captured and used as energy resource. 


\subsubsection{Operating cost}

\subsubsection{Effect of influent sulphate content on operating cost}

Figure 2 illustrates the operating cost of the different evaluated scenarios when treating 100 (Figure 2a), 50 (Figure 2b) and 10\% (Figure 2c) of the original sulphate content in the UWW and OFMSW. These operating costs include the following: energy consumption (considering energy recovery from methane); O\&M (operating and maintenance) of the technology considered for recovering energy from methane (degassing membranes and microturbine-based CHP); membrane cleaning reagents (considering 100, 150 and $200 \%$ of the original fouling rate when feeding OFMSW to the system); and sludge handling and disposal. As Figure 2 shows, Scenarios 4 and 5 (operating at SRT of 70 days and PF of 40 and $80 \%$, respectively) presented the lowest operating costs due to the high biogas production achieved as a result of operating at high SRT and PF. Scenarios 1 and 3 (operating at SRT of 40 days and PF of 0 and 40\%, respectively) presented the highest operating costs due to the low biogas and high sludge productions reached as a result of operating at low SRT and PF.

For instance, as shown in Figure 2a (treating 100\% of the sulphate content in the UWW and OFMSW), Scenarios 4 and 5 presented the lowest operating costs (€0.011 and 0.002 per $\mathrm{m}^{3}$, respectively), whilst Scenarios 1 and 3 presented the highest ones $(€ 0.051$ and 0.029 per $\mathrm{m}^{3}$, respectively). Scenario 2 resulted in $€ 0.019$ per $\mathrm{m}^{3}$. Similarly, as shown in Figure $2 \mathrm{~b}$ (treating $50 \%$ of the original sulphate content in the UWW and OFMSW), Scenarios 4 and 5 resulted in savings in operating costs ( $€ 0.001$ and 0.014 per $\mathrm{m}^{3}$, respectively), in opposition to Scenarios 1 and 3, which presented the highest operating cost ( $€ 0.040$ and 0.019 per $\mathrm{m}^{3}$, respectively). Scenario 2 resulted in $€ 0.006$ 
per $\mathrm{m}^{3}$. On the other hand, as shown in Figure $2 \mathrm{c}$ (treating $10 \%$ of the original sulphate content in the UWW and OFMSW), Scenarios 4 and 5 resulted in savings in operating costs (savings of $€ 0.011$ and 0.023 per $\mathrm{m}^{3}$, respectively), contrary to Scenarios 1 and 3, which presented the highest operating costs (€0.032 and 0.010 per $\mathrm{m}^{3}$, respectively). Scenario 2 resulted in cost savings of $€ 0.004$ per $\mathrm{m}^{3}$.

On the other hand, it is worth pointing out the reduction in the operating cost when treating low-sulphate UWW, since the amount of influent COD transformed into methane increases significantly, thus decreasing energy consumption (see Table 2). As Figure 2 shows, a significant decrease in the AnMBR operating cost could be achieved in scenario 4 and 5 when treating low-sulphate UWW. Indeed, the results show savings in operating costs of $€ 0.011$ and 0.023 per $\mathrm{m}^{3}$, in scenario 4 and 5 respectively.

\subsubsection{Effect of membrane fouling on operating cost}

An important increase in the AnMBR operating cost could occur when operating at 150 (Scenarios 3, 4 and 5) and 200\% (Scenario 5) of the original fouling rate (see Figure 2). For instance, in Scenario 5 (treating $100 \%$ of the sulphate content in the UWW and OFMSW), the operating cost could increase up to $€ 0.003$ and 0.008 per $\mathrm{m}^{3}$ when operating at 150 and $200 \%$ of the original fouling rate, respectively. In Scenario 4 (treating 100\% of the original sulphate content in the UWW and OFMSW), the operating cost could increase from $€ 0.011$ to 0.017 per $\mathrm{m}^{3}$ when operating at $150 \%$ of the original fouling rate. 
However, even when doubling the fouling rate, Scenario 5, followed to a lesser extent by Scenario 4, maintained the lowest operating costs, comparing with the rest of scenarios. Although OFMSW was not fed to the system in Scenario 1 (therefore an increase in fouling rate was not considered), this scenario maintained the highest operating cost, followed by Scenario 3.

As mentioned earlier, it is worth to point out that, excluding Scenario 1 and 3, AnMBR technology for the operating conditions considered in this study, is likely to present considerable cost savings when treating UWW and/or UWW and OFMSW (up to $€ 0.023$ per $\mathrm{m}^{3}$ of treated water).

\subsubsection{Life cycle analysis results}

As mentioned earlier, the SimaPro software (using Ecoinvent data) was used to assess the potential environmental impact of the AnMBR system evaluated in this study. Eutrophication was considered the most relevant impact category in every evaluated scenario, followed by marine aquatic ecotoxicity. GWP, abiotic depletion and acidification were not among the most relevant impact categories. However, they are usually regarded as a significant environmental issue from a political and social point of view, thus they were also evaluated in this study.

\subsubsection{Environmental impacts of the factors contemplated in the inventory analysis} The environmental impacts of the factors contemplated in the inventory analysis through the impact categories selected in this study (i.e. eutrophication, marine aquatic 
ecotoxicity, GWP, abiotic depletion and acidification) are discussed in the following paragraphs.

\section{Eutrophication}

This impact category has been considered the most relevant impact category in the majority of published LCAs on WWTPs (Rodriguez-Garcia et al., 2011). In this study, the effluent discharge $\left(\mathrm{N}_{\mathrm{T}}, \mathrm{P}_{\mathrm{T}}\right.$ and COD) was the factor that affected eutrophication most $\left(94 \%\right.$ in average in every scenario, representing $\mathrm{N}_{\mathrm{T}}$ the highest contribution $(55 \%$ in average)), followed to a lesser extent by $\mathrm{PO}^{3-}{ }_{4}$ leakage and $\mathrm{NH}_{3}$ emissions from sludge disposal to farmland (5\% in average). The rest of factors (e.g chemical and power consumption) had barely any environmental impact on the system.

\section{Marine aquatic ecotoxicity}

As Figure 3a shows, the impacts in marine aquatic ecotoxicity were mostly associated with sludge disposal (71\% in average), in particular when sludge is landfilled (with an average contribution of 54\%), followed by heavy metal emissions to soil (average contribution of $16 \%$ ) when the sludge is applied to farmland. Followed to a lesser extent was the power requirements with an average contribution of $28 \%$. Note that fertiliser and energy avoided presented a meaningful positive environmental impact (representing an average reduction of 23 and $34 \%$ of the total environmental load through this impact category, respectively). The rest of factors (e.g. chemical consumption such as polyelectrolyte and membrane cleaning reagent) had barely any environmental impact on the system. 
$\underline{G W P}$

As Figure 3b shows, the impacts in GWP were mostly related to: (1) power requirement (average contribution of 39\%); (2) sludge disposal when the sludge is landfilled (average contribution of 22\%); (3) sludge disposal when the sludge is applied to farmland, in particular the $\mathrm{N}_{2} \mathrm{O}$ emissions to air (average contribution of 21\%) (4) methane emissions to air because of the methane dissolved in the effluent (average contribution of $14 \%$ ); and polyelectrolyte consumption (average contribution of $2 \%$ ). As regards fertiliser and energy avoided, they presented a meaningful positive environmental impact also in this impact category (representing an average reduction of 25 and $48 \%$ of total environmental load through GWP, respectively). Membrane cleaning reagent had barely any environmental impact on the system.

\section{$\underline{\text { Abiotic depletion }}$}

As Figure $3 \mathrm{c}$ shows, power requirement (average contribution of $87 \%$ ) followed to a lesser extent by both sludge handling through polyelectrolyte consumption (average contribution of $8 \%$ ) and sludge disposal (average contribution of $4 \%$ ) were the factors that affected the abiotic depletion most. Also in this case, fertiliser and energy avoided presented a meaningful positive environmental impact (representing an average reduction of 57 and $103 \%$ of total environmental load through abiotic depletion, respectively). The rest of factors had barely any environmental impact on the system.

\section{Acidification}

As Figure $3 \mathrm{~d}$ shows, the environmental impact in acidification was mostly associated with sludge disposal, in particular with the $\mathrm{NH}_{3}$ emissions from sludge application to 
farmland (in average 88\%). In accordance with the rest of evaluated impact categories, fertiliser and energy avoided presented a positive environmental impact (an average reduction of 6 and 14\% of total environmental load through acidification, respectively, was achieved in this case).

\subsubsection{Overall LCA results among the evaluated scenarios}

By way of example, Figure 4 illustrates the LCA results of the different operating scenarios evaluated in the AnMBR system when treating sulphate-rich influent (i.e. containing $100 \%$ of the original sulphate content in the UWW and OFMSW). Results in Figure 4 have been weighted (based on normalised values per $\mathrm{m}^{3}$ ) applying a value of $100 \%$ to the scenario that resulted in the highest environmental impact.

As Figure 4 shows, Scenario 1 (operating at SRT of 40 days and PF of 0\%) presented the highest environmental impact through abiotic depletion, GWP, acidification and marine aquatic ecotoxicity due to: (1) a high sludge production (as a result of operating at the lowest SRT and temperature compared to the rest of scenarios), resulting therefore in high impacts due to sludge handling and disposal; and (2) a low biogas production (besides the lowest SRT and temperature, OFMSW was not introduced to the system), thus resulting in lower positive impacts due to energy recovery from methane. Scenario 3 (operating at SRT of 40 days and PF of $40 \%$ ) was the second worse in the LCA rank because of a higher sludge production (affecting impacts due to sludge disposal and polyelectrolyte consumption, as a result of operating at the lowest SRT) and a higher energy demand (operating at SRT of 40 days instead of 70 days results in much lower final methane production) compared to the rest of evaluated scenarios (except scenario 1). On the other hand, a significant reduction in 
environmental impacts (especially abiotic depletion) was observed in Scenario 4 and 5 (operating at SRT of 70 days and PF of 40 and $80 \%$, respectively). Specifically, the environmental load for abiotic depletion decreased around 127 and 147\%, respectively, in comparison with Scenario 1, since, as commented before, the energy avoided had a meaningful positive impact in LCA results. Note that Scenario 4 presented the highest eutrophication impact since the $\mathrm{N}_{T}$ content in the influent was higher in this scenario than in the rest (see table 1).

Hence, the results of this study revealed that increasing SRT (e.g. from 40 to 70 days) and treating UWW jointly with OFMSW enhances the environmental performance of AnMBR systems: the environmental impact through abiotic depletion, GWP, acidification and marine aquatic ecotoxicity are considerably reduced.

\subsubsection{Effect of influent sulphate content on LCA results}

The LCA results obtained when using sulphate-rich influent (i.e. 100\% of the original content in the UWW and OFMSW) were compared to the theoretical results obtained if treating medium- and low-sulphate influent. Figure 5 illustrates the LCA results of Scenarios 1 and 5 (worst and best case studies) if treating 100, 50 and $10 \%$ of the original sulphate content in the UWW and OFMSW. As Figure 5 shows, a significant reduction in abiotic depletion was observed when treating low-sulphate influent in comparison with treating high-sulphate influent (see Scenarios 1 and 5 in Figure 5). For instance, the environmental load for abiotic depletion decreased around 41-46 and 74$82 \%$, when treating 50 and $10 \%$ of the original sulphate content in the UWW and OFMSW, respectively. The effect of treating low- or high-sulphate influent was only 
noticeable in abiotic depletion since the higher the amount of influent COD transformed into methane, the lower the energy consumption (reducing therefore the consumption of fossils fuels). Although it could have been expected that treating low-sulphate influent had a noticeable effect on GWP (since energy consumption is an important factor affecting this impact category), a higher amount of dissolved methane in the effluent was observed, which was therefore emitted into the atmosphere offsetting the positive effect of the increased energy recovery potential from methane capture.

\subsubsection{Effect of membrane fouling on LCA results}

The effect of treating UWW jointly with OFMSW on membrane fouling presented an effect on reactant consumption, since the higher the fouling rate considered, the higher the chemical reagent consumption for membrane cleaning. However, as mentioned earlier, reactant consumption for membrane cleaning had barely any environmental impact on the system.

\section{Conclusions}

The operating cost of an AnMBR system treating UWW and OFMSW was evaluated at different operating conditions. The results revealed that even considering significant fouling rates when OFMSW is incorporated, AnMBR technology is likely to be a net energy producer, resulting in considerable cost savings (up to $€ 0.023$ per $\mathrm{m}^{3}$ of treated water) when treating low-sulphate influent. Regarding LCA results, operating at high SRT (70 days) and treating UWW jointly with OFMSW enhances the environmental performance of AnMBR systems: the environmental impact through abiotic depletion, GWP and marine aquatic ecotoxicity are considerably reduced. 


\section{Acknowledgements}

This research work was supported by Generalitat Valenciana (project

PROMETEO/2012/029), which is gratefully acknowledged. Besides, financial support from the Spanish Ministry of Education, Culture and Sport via a pre-doctoral FPU grant to the first author (AP-2010-2148) is gratefully acknowledged.

\section{References}

Cirne, D.G., Paloumet, X., Björnsson, L., Alves, M.M., Mattiasson, B., 2007. Anaerobic digestion of lipid-rich waste-Effects of lipid concentration. Renew. Energ. 32, 965-975.

Corominas, L., Foley, J., Guest, J.S., Hospido, A., Larsen, H.F., Morera, S., Shaw, A., 2013. Life cycle assessment applied to wastewater treatment: State of the art. Water Res. 47, 5480-5495.

Dereli, R.K., van der Zee, F.P., Heffernan, B., Grelot, A., van Lier, J.B., 2014. Effect of sludge retention time on the biological performance of anaerobic membrane bioreactors treating corn-toethanol thin stillage with high lipid content. Water Res. 49, 453-464.

Fenu, A., Roels, J., Wambecq, T., De Gussem, K., Thoeye, C., De Gueldre, G., Vand De Steene, B., 2010. Energy audit of a full scale MBR system. Desalination 262, 121-128.

Ferrer, J., Seco, A., Serralta, J., Ribes, J., Manga, J., Asensi, E., Morenilla, J.J., Llavador, F., 2008. DESASS: A software tool for designing, simulating and optimising WWTPs. Environ. Modell. Softw. 23, $19-26$.

Gallego, A., Hospido, A.,Moreira, MT., Feijoo,G., 2008. Environmental performance of wastewater treatment plants for small populations. Resour. Conser. Recy. 52, 931-940.

Garrido-Baserba, M., Hospido, A., Reif, R., Molinos-Senante, M., Comas, J., Poch, M., 2014. Including the environmental criteria when selecting a wastewater treatment plant. Environ. Modell. Softw. 56, 74-82.

Giménez, J.B., Martí, N., Ferrer, J., Seco, A., 2012. Methane recovery efficiency in a submerged anaerobic membrane bioreactor (SAnMBR) treating sulphate-rich urban wastewater: Evaluation of methane losses with the effluent. Bioresource Technol. 118, 67-72. 
Giménez, J.B., Robles, A., Carretero, L., Durán, F., Ruano, M.V., Gatti, M.N., Ribes, J., Ferrer, J., Seco, A., 2011. Experimental study of the anaerobic urban wastewater treatment in a submerged hollow-fibre membrane bioreactor at pilot scale. Bioresource Technol. 102, 8799- 8806.

He, Y., Xu, P., Li, C., Zhang, B., 2005. High-concentration food wastewater treatment by an anaerobic membrane bioreactor. Water Res. 39, 4110-4118

Hulshoff Pol, L.W.,1998. Treatment of sulphate-rich wastewaters: microbial and process technological aspects TMR Summer School Programme, The Biological Sulfur Cycle: Environmental Science and Technology, April, Wageningen, The Netherlands.

ISO, 2006. International Organization for Standardization (ISO) 14040: Environmental Management - Life Cycle Assessment e Principles and Framework (Geneva).

Jeison, D., 2007. Anaerobic membrane bioreactor for wastewater treatment: Feasibility and potential applications. $\mathrm{PhD}$ thesis. Wageningen University, Wageningen, The Netherlands.

Judd S., 2011. The MBR site. Available on: http://www.thembrsite.com (acceded 6 March 2013).

Judd, S., Judd, C., 2011. Principles and Applications of Membrane Bioreactors in Water and Wastewater Treatment. Second Edition, Elsevier, London, UK.

Lin, H., Peng, W., Zhang, M., Chen, J., Huachang, H., Zhang, Y., 2013. A review on anaerobic membrane bioreactors: Applications, membrane fouling and future perspectives. Desalination 314, $169-188$.

Lin, H., Liao, B., Chen, J., Gao, W., Wang, L., Wang, F., Lu, X., 2011. New insights into membrane fouling in a submerged anaerobic membrane bioreactor based on characterization of cake sludge and bulk sludge, Bioresource Technol. 102, 2373-2379.

MAGRAMA, 2015. Official website of the Ministry of Agriculture, Food and Environment. Spanish government, Madrid. Available on: http://www.magrama.gob.es/es/calidad-y-evaluacionambiental/temas/prevencion-y-gestion-residuos/flujos/lodos-depuradora/, 2015

Miliarium Aureum, S.L., (n.d.). Approximate cost of WWTP (Coste estimativo EDAR). In Miliarium.com - Ingeniería Civil y Medio Ambiente. Available on: http://www.miliarium.com/Proyectos/Depuradoras/introduccion/edar.asp, 2013. 
Moñino, P., Aguado, D., Barat, R., Jiménez, E., Giménez, J.B., Seco, A., Ferrer, J., 2016.

Treatment of the organic fraction of municipal solid waste jointly with urban wastewater by AnMBR technology: Pilot-plant experience. Submitted.

Ozgun, H., Dereli, R.K., Ersahin, M.E., Kinaci, C., Spanjers, H., van Lier, J.B., 2013. A review of anaerobic membrane bioreactors for municipal wastewater treatment: Integration options, limitations and expectations. Sep. Purif. Technol. 118, 89-104.

Pretel, R., Robles, A., Ruano, M.V., Seco, A., Ferrer, J., 2013. Environmental impact of submerged anaerobic MBR (AnMBR) technology used to treat urban wastewater at different temperatures. Bioresource Technol. 149, 532-40.

Pretel, R., Robles, A., Ruano, M.V., Seco, A., Ferrer, J., 2014. The operating cost of an anaerobic membrane bioreactor (AnMBR) treating sulphate-rich urban wastewater. Sep. Purif. Technol. 126, 3038.

Pretel, R., Robles, A., Ruano, M.V., Seco, A., Ferrer, J., 2016a. Filtration process cost in submerged anaerobic membrane bioreactors (AnMBRs) for urban wastewater treatment. Sep. Sci. Technol. In press.

Pretel, R., Robles, A., Ruano, M.V., Seco, A., Ferrer, J. 2016b. A plant-wide energy model for WWTPs: application to AnMBR technology. Environ. Technol. In press.

Pretel, R., Robles, A., Ruano, M.V., Seco, A., Ferrer, J. 2016c. Economic and environmental sustainability of submerged anaerobic MBR-based (AnMBR-based) technology as compared to aerobic-based technologies for moderate-/high-loaded urban wastewater treatment. J. Environ. Manage. 166, $45-54$.

Ramos, C., García, A., Diez, V., 2014. Performance of an AnMBR pilot plant treating high strength lipid wastewater: Biological and filtration, Processes. Water Res. 67, 203-215.

Raskin, L.M., 2012. Anaerobic Membrane Bioreactors for Sustainable Wastewater Treatment, WERF Report U4R08.

Robles, A., Ruano, M.V., Ribes, J., Ferrer, J., 2012. Sub-critical long-term operation of industrial scale hollow-fibre membranes in a submerged anaerobic MBR (HF-SAnMBR) system. Sep. Purif. Technol. 100, 88-96. 
Robles, A., Durán, F., Ruano, M.V., Ribes, J., Rosado, A., Seco, A., Ferrer, J., 2015.

Instrumentation, control, and automation for submerged anaerobic membrane bioreactors. Environ. Technol. 36, 1795-1806.

Rodriguez-Garcia, G., Molinos-Senante, M., Hospido, A., Hernández-Sancho, F., Moreira, M.T., Feijoo, G., 2011. Environmental and economic profile of six typologies of wastewater treatment plants. Water Res. 45, 5997-6010.

Sainz-Lastre, J.A., 2005. Technologies for sustainability. Processes and unit operations in wastewater treatment (Tecnologías para la sostenibilidad. Procesos y operaciones unitarias en depuración de aguas residuales). Colección EOI Medio Ambiente. Madrid, Spain.

Smith, A. L., Skerlos, S.J., Raskin, L., 2013. Psychrophilic anaerobic membrane bioreactor treatment of domestic wastewater. Water Res. 47, 1655-1665.

Standard methods for the Examination of Water and Wastewater, $21^{\text {th }}$ edn, American Public Health Association/American Water Works Association/Water Environmental Federation, Washington DC, USA, 2005.

Stuckey, D.C., 2012. Recent developments in anaerobic membrane reactors, Bioresource Technol. $122,137-148$. 


\section{Table and Figure captions}

Table 1. Average characteristics of the AnMBR influent in the five scenarios evaluated in this study.

Table 2. Main biological operating conditions in the scenarios selected to conduct the LCA of the

AnMBR system. SRT: Sludge retention time; HRT: hydraulic retention time; T: temperature; PF: penetration factor.

Table 3. Main filtration operating conditions in the scenarios selected to conduct the LCA of the AnMBR system. $\mathbf{J}_{\mathbf{2 0}}: 20^{\circ} \mathrm{C}$-standardised transmembrane flux; $\mathbf{S G D}_{\mathbf{m}}$ : specific gas demand per square metre of membrane area; TMP: transmembrane pressure; MLTS $_{\text {AnR: }}$ mixed liquor total solids concentration in the anaerobic reactor; $\mathbf{B R F}_{\text {AnR: }}$ biogas recycling flow to the anaerobic reactor: $\mathbf{S R F}$ AnR: sludge recycling flow in anaerobic reactor; and $\mathbf{S R F}$ мT: sludge recycling flow in membrane tank.

Figure 1. Energy balance results of the five operating scenarios evaluated in the AnMBR system treating low-, moderate- and high-sulphate UWW and OFMSW (10, 50 and 100\% of the original sulphate content in the UWW and OFMSW, respectively).

Figure 2. Operating costs of the five operating scenarios evaluated in the AnMBR system, considering 100, 150 and $200 \%$ of the original fouling rate and treating: (a) 100, (b) 50, and (c) $10 \%$ of the original sulphate content in the UWW and OFMSW. FR: Fouling Rate.

Figure 3. Weighted average distribution of the factors contemplated in the inventory analysis of the five operating scenarios evaluated in the AnMBR system treating sulphate-rich UWW and OFMSW through: (a) marine aquatic ecotoxicity; (b) GWP; (c) abiotic depletion; and (d) acidification.

Figure 4. LCA results of the five operating scenarios evaluated in the AnMBR system treating sulphaterich UWW and OFMSW (\% based on normalised values per $\mathrm{m}^{3}$ ).

Figure 5. LCA results of Scenarios 1 and 5 in the AnMBR system treating 100, 50 and 10\% of the original sulphate content in the UWW and OFMSW (\% based on normalised values per $\mathrm{m}^{3}$ ). 
Table 1. Average characteristics of the AnMBR influent in the five scenarios evaluated in this study.

\begin{tabular}{|c|c|c|c|c|c|}
\hline Parameter & Scenario 1 & Scenario 2 & Scenario 3 & Scenario 4 & Scenario 5 \\
\hline Treatment flow rate $\left(\mathrm{m}^{3} \cdot \mathrm{day}^{-1}\right)$ & 1.6 & 2.2 & 2.9 & 2.3 & 2.2 \\
\hline TSS $\left(\mathrm{mg} \cdot \mathbf{L}^{-1}\right)$ & 260 & 226 & 318 & 414 & 627 \\
\hline $\operatorname{VSS}\left(\mathbf{m g} \cdot \mathbf{L}^{-1}\right)$ & 207 & 196 & 279 & 352 & 530 \\
\hline $\operatorname{COD}\left(\mathrm{mg} \cdot \mathrm{L}^{-1}\right)$ & 643 & 635.9 & 650 & 853 & 947 \\
\hline $\mathrm{SO}_{4-S}\left(\mathbf{m g} \cdot \mathbf{L}^{-1}\right)$ & 98 & 114 & 89 & 109 & 99 \\
\hline $\mathbf{N}_{\mathrm{T}}\left(\mathbf{m g} \cdot \mathbf{L}^{-1}\right)$ & 49.6 & 44.5 & 40.8 & 69.1 & 53.5 \\
\hline $\mathbf{P}_{\mathrm{T}}\left(\mathbf{m g} \cdot \mathbf{L}^{-1}\right)$ & 5.0 & 5.4 & 7.9 & 7.3 & 7.9 \\
\hline
\end{tabular}


Table 2. Main biological operating conditions and resulting performance indexes in the scenarios selected to conduct the LCA of the AnMBR system. SRT: Sludge retention time; HRT: hydraulic retention time; T: temperature; PF: penetration factor.

\begin{tabular}{|c|c|c|c|c|c|c|c|c|c|c|c|}
\hline & \multirow{3}{*}{$\begin{array}{l}\text { SRT } \\
\text { (days) }\end{array}$} & \multirow{3}{*}{$\begin{array}{c}\text { HRT } \\
\text { (hours) }\end{array}$} & \multirow{3}{*}{$\begin{array}{c}\mathbf{T} \\
\left({ }^{\circ} \mathrm{C}\right)\end{array}$} & \multirow{3}{*}{$\begin{array}{l}\mathrm{PF} \\
\\
(\%)\end{array}$} & \multicolumn{3}{|c|}{$\begin{array}{l}\text { Vh4,BIOGAS } \\
\text { (a) }\end{array}$} & \multicolumn{3}{|c|}{ 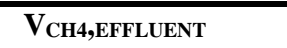 } & \multirow{3}{*}{ 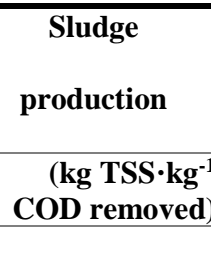 } \\
\hline & & & & & \multicolumn{3}{|c|}{$\left(\mathbf{L} \cdot \mathbf{m}^{-3}\right)$} & \multicolumn{2}{|c|}{$\left(\mathbf{L} \cdot \mathbf{m}^{-3}\right)$} & & \\
\hline & & & & & $100 \% *$ & $50 \% * *$ & $10 \% * * *$ & $100 \%$ & $50 \%$ & $10 \%$ & \\
\hline Scenario 1 & 40 & 22 & 25 & 0 & 11 & 24 & 34 & 19 & 41 & 59 & 0.92 \\
\hline Scenario 2 & 70 & 22 & 28 & 0 & 31 & 54 & 72 & 25 & 43 & 57 & 0.37 \\
\hline Scenario 3 & 40 & 18 & 29 & 40 & 26 & 46 & 62 & 14 & 26 & 34 & 0.47 \\
\hline Scenario 4 & 70 & 22 & 28 & 40 & 62 & 91 & 114 & 21 & 30 & 38 & 0.27 \\
\hline Scenario 5 & 70 & 24 & 27 & 80 & 96 & 125 & 147 & 22 & 29 & 34 & 0.21 \\
\hline
\end{tabular}

Treating $100 \%(*), 50 \%(* *)$ and $10 \%(* * *)$ of the original sulphate content in the UWW and OFMSW. 
Table 3. Main filtration operating conditions in the scenarios selected to conduct the LCA of the AnMBR system. $\mathbf{J}_{\mathbf{2 0}}$ : $20^{\circ} \mathrm{C}$-standardised transmembrane flux; SGDm: specific gas demand per square metre of membrane area; TMP: transmembrane pressure; MLTSAnR: mixed liquor total solids concentration in the anaerobic reactor; BRF AnR: biogas recycling flow to the anaerobic reactor: $\mathbf{S R F}$ AnR: sludge recycling flow in anaerobic reactor; and SRFMT: sludge recycling flow in membrane tank.

\begin{tabular}{|c|c|c|c|c|c|c|c|}
\hline & $\mathbf{J}_{20}$ & SGDm & TMP & MLTS $_{\text {AnR }}$ & BRF $_{\text {AnR }}$ & $\mathbf{S R F}_{\mathrm{AnR}}$ & SRF $_{M T}$ \\
\hline & (LMH) & $\left(\mathbf{m}^{3} \cdot \mathbf{h}^{-1} \cdot \mathbf{m}^{-2}\right)$ & (bar) & $\left(\mathbf{g} \cdot \mathbf{L}^{-1}\right)$ & $\left(\mathbf{m}^{3} \cdot \mathbf{h}^{-1}\right)$ & $\left(\mathbf{m}^{3} \cdot \mathbf{h}^{-1}\right)$ & $\left(\mathbf{m}^{3} \cdot \mathbf{h}^{-1}\right)$ \\
\hline Scenario 1 & 15.8 & 0.10 & 0.10 & 17 & 1.5 & 1 & 2.5 \\
\hline Scenario 2 & 19.4 & 0.10 & 0.10 & 13 & 1.5 & 1 & 2.5 \\
\hline Scenario 3 & 16.7 & 0.10 & 0.10 & 16 & 1.5 & 1 & 2.5 \\
\hline Scenario 4 & 17.6 & 0.10 & 0.10 & 15 & 1.5 & 1 & 2.5 \\
\hline Scenario 5 & 18.5 & 0.10 & 0.10 & 14 & 1.5 & 1 & 2.5 \\
\hline
\end{tabular}




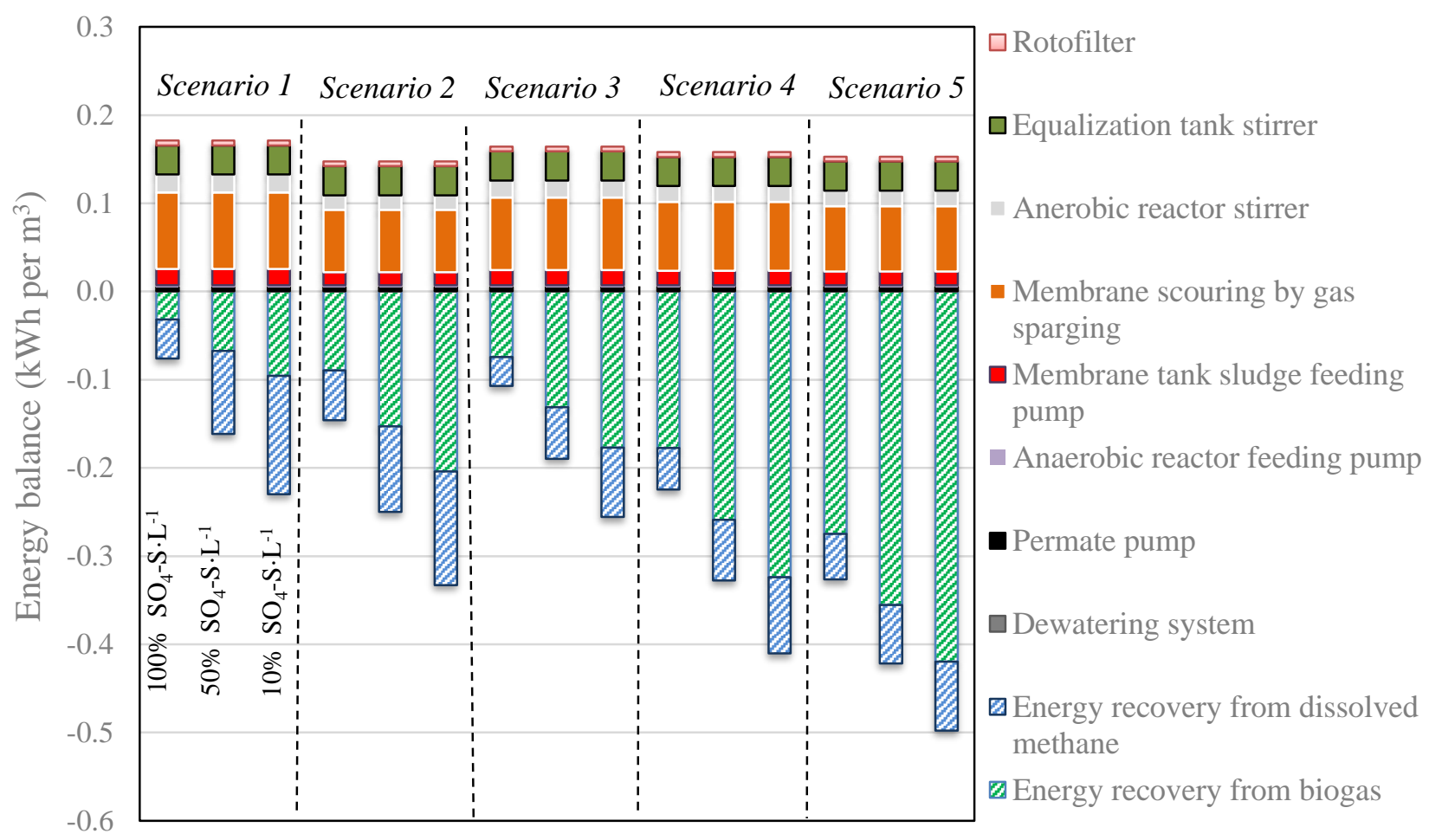

Figure 1. Energy balance results of the five operating scenarios evaluated in the AnMBR system treating low-, moderate- and high-sulphate UWW and OFMSW (10, 50 and 100\% of the original sulphate content in the UWW and OFMSW, respectively). 


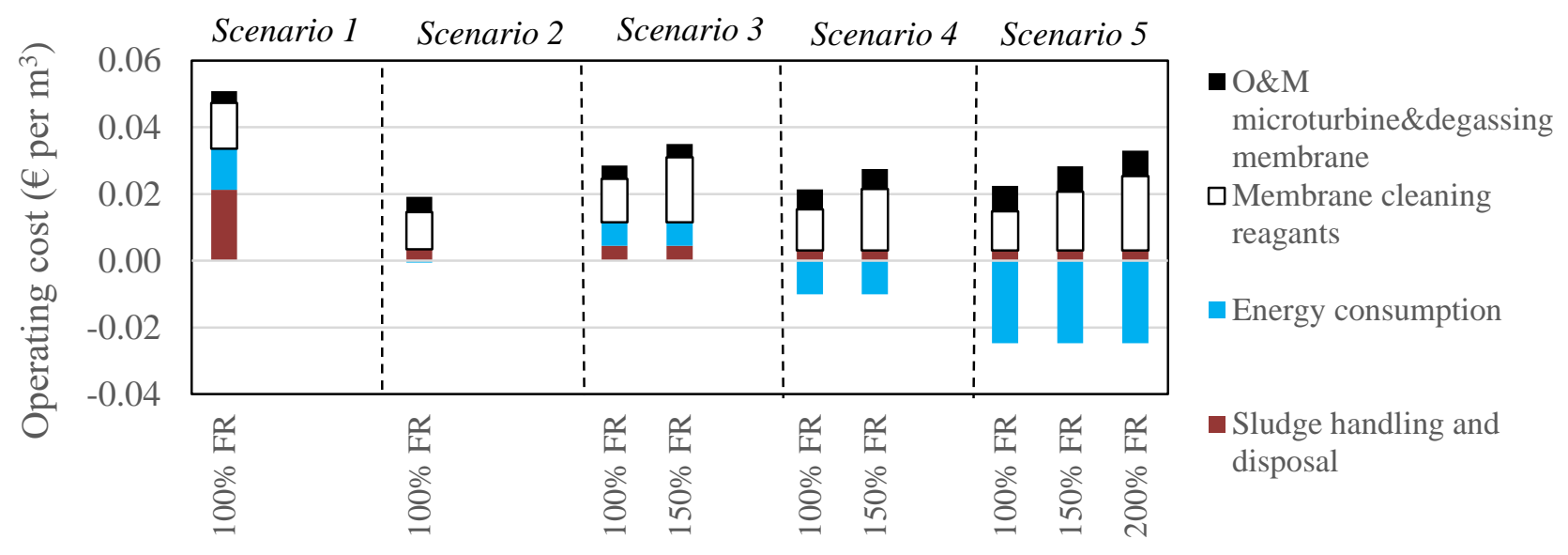

(a)

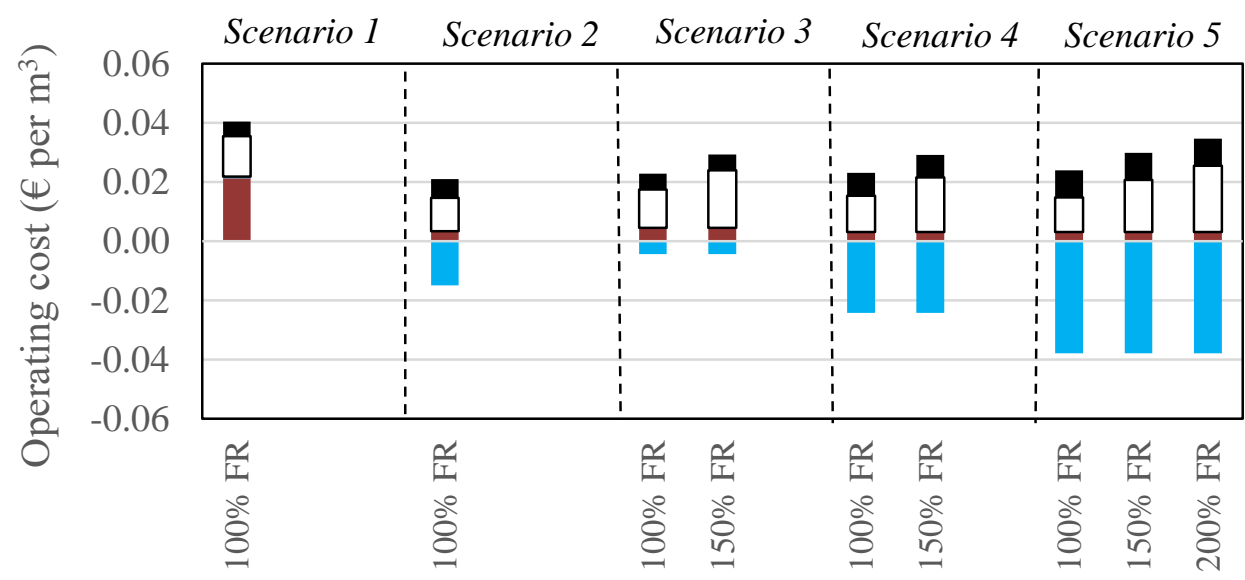

O\&M

microturbine\&degassing membrane

$\square$ Membrane cleaning reagants

Energy consumption

- Sludge handling and disposal

(b)

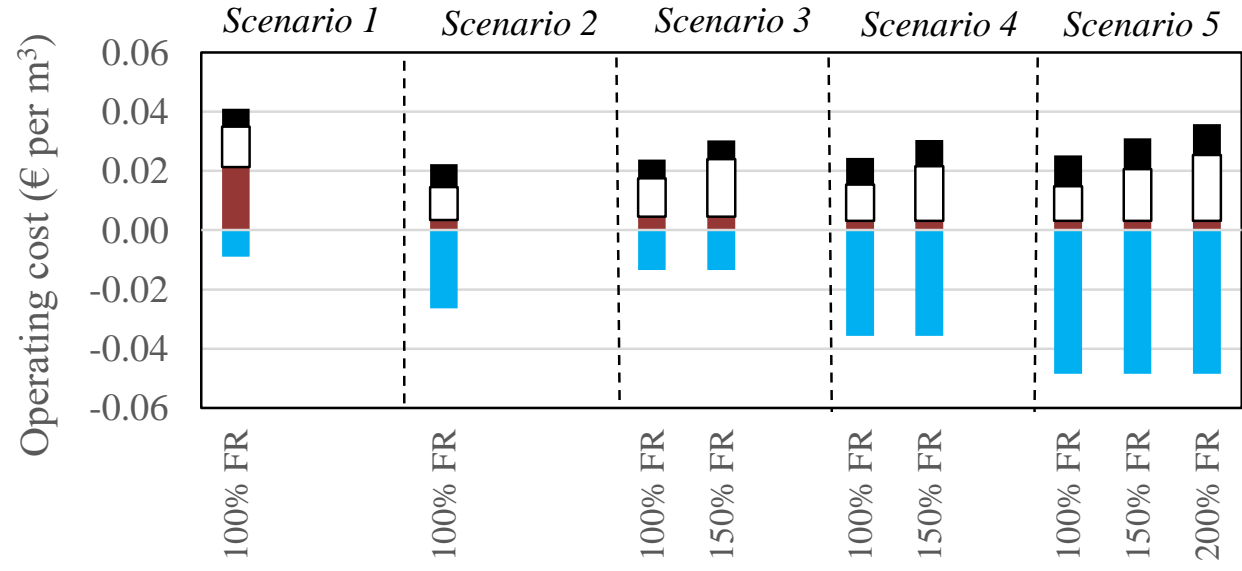

- O\&M

microturbine\&degassing membrane

口Membrane cleaning reagants

Energy consumption

- Sludge handling and disposal

(c)

Figure 2. Operating costs of the five operating scenarios evaluated in the AnMBR system, considering 100,150 and $200 \%$ of the original fouling rate and treating: (a) 100, (b) 50, and (c) $10 \%$ of the original sulphate content in the UWW and OFMSW. FR: Fouling Rate. 


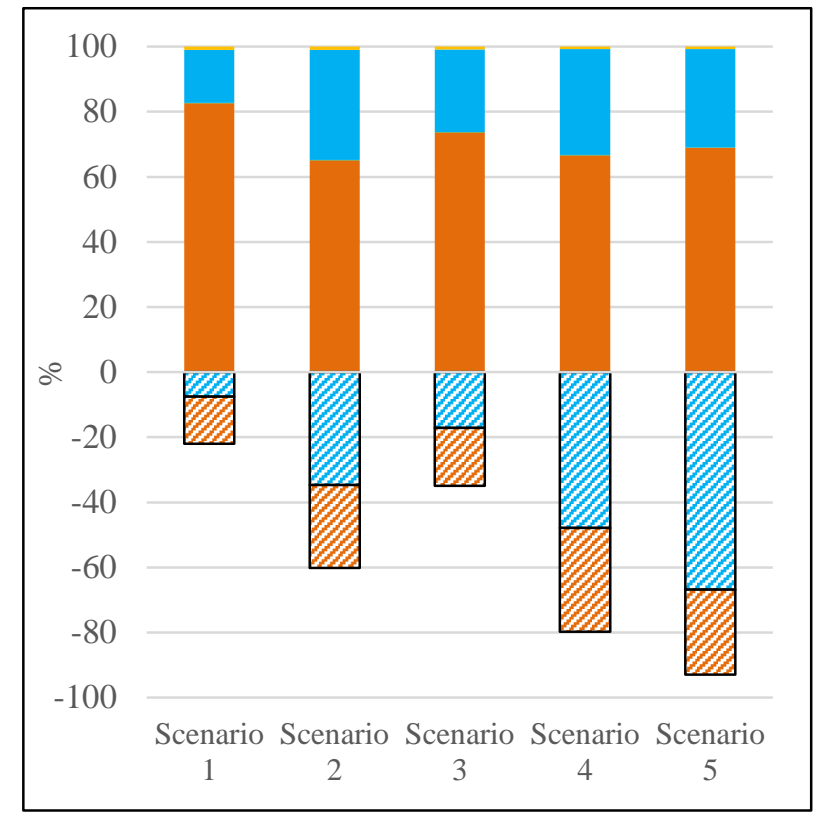

(a)

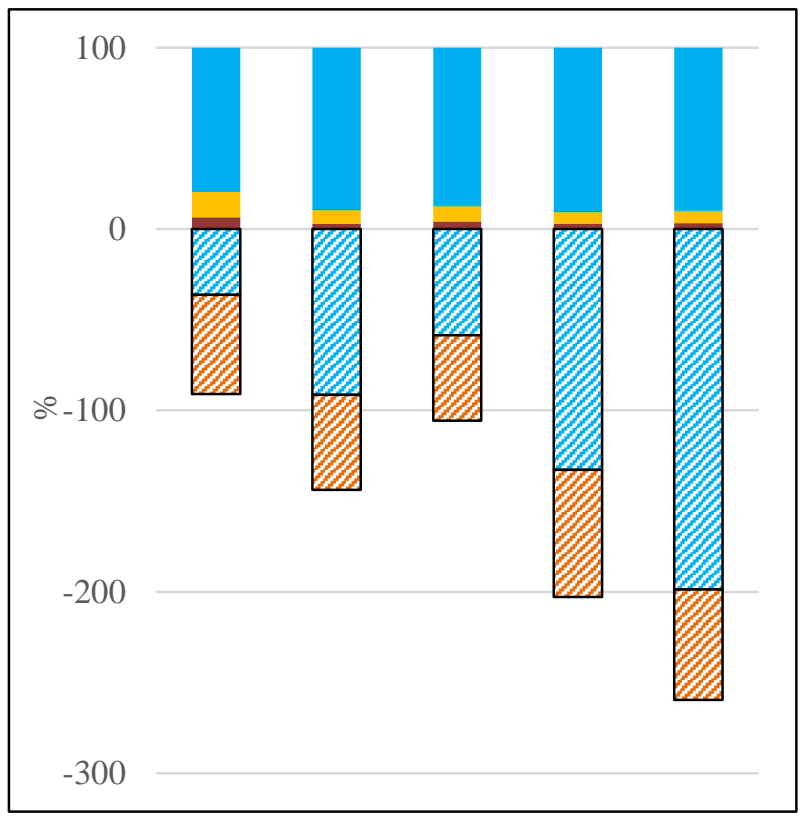

(c)

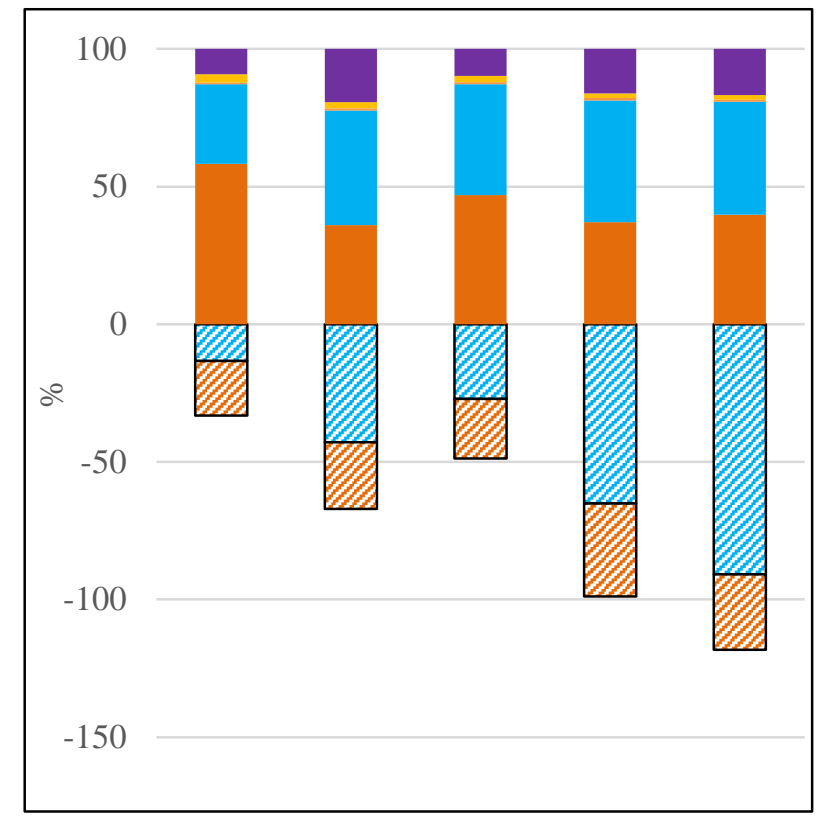

(b)

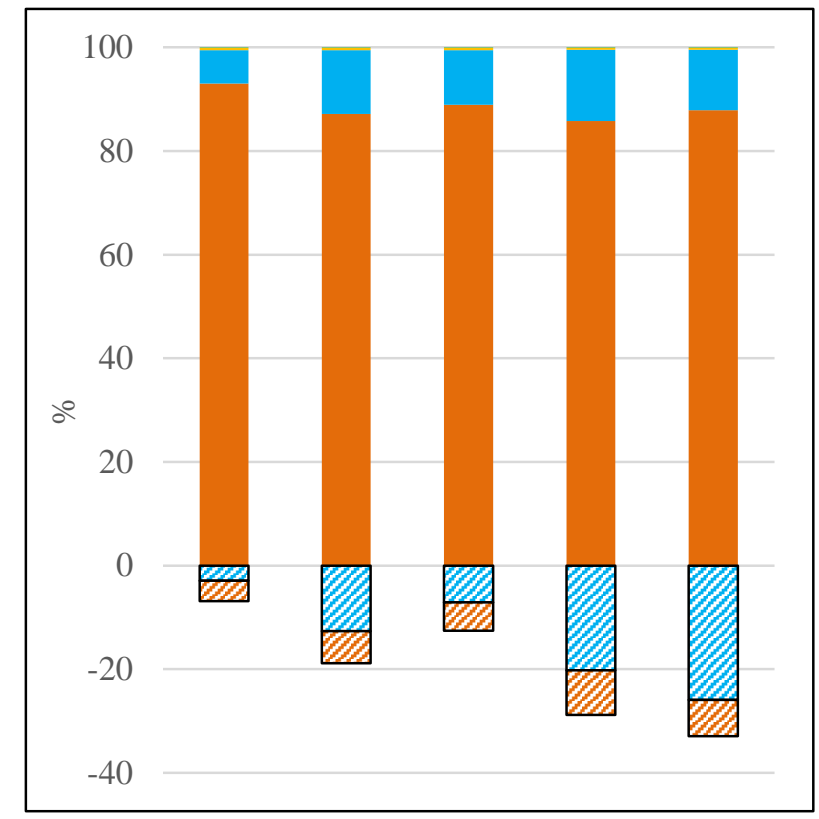

(d)

- Emissions to air from methane dissolved in the effluent

- Power requirement

- Effluent discharge

- Sludge disposal

- Membrane cleaning reagant

$\square$ Encrgy avoided

- Polyelectrolyte consumption

Figure 3. Weighted average distribution of the factors contemplated in the inventory analysis of the five operating scenarios evaluated in the AnMBR system treating sulphate-rich UWW and OFMSW through: (a) marine aquatic ecotoxicity; (b) GWP; (c) abiotic depletion; and (d) acidification. 


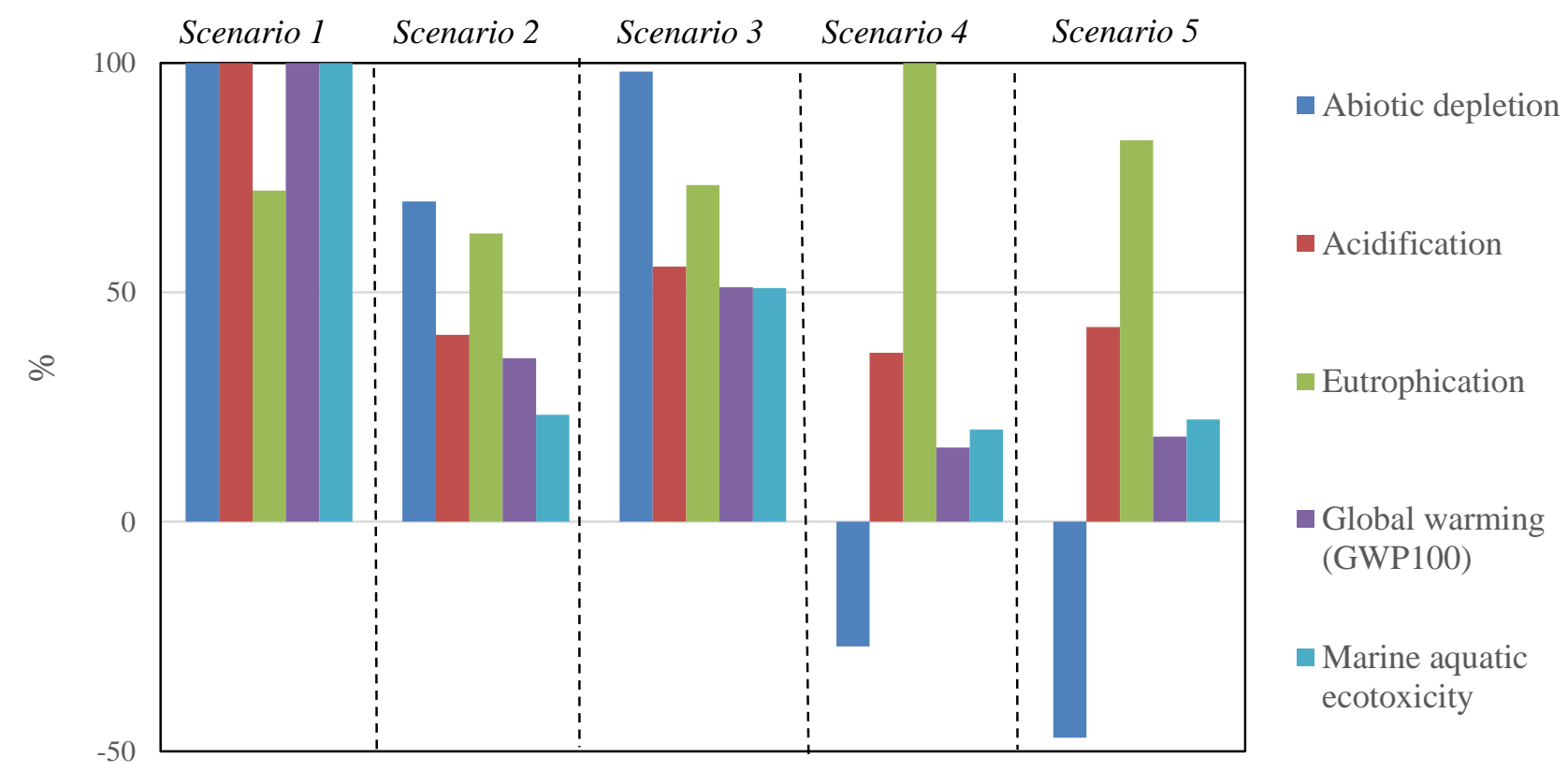

Figure 4. LCA results of the five operating scenarios evaluated in the AnMBR system treating sulphate-rich UWW and OFMSW (\% based on normalised values per $\mathrm{m}^{3}$ ). 


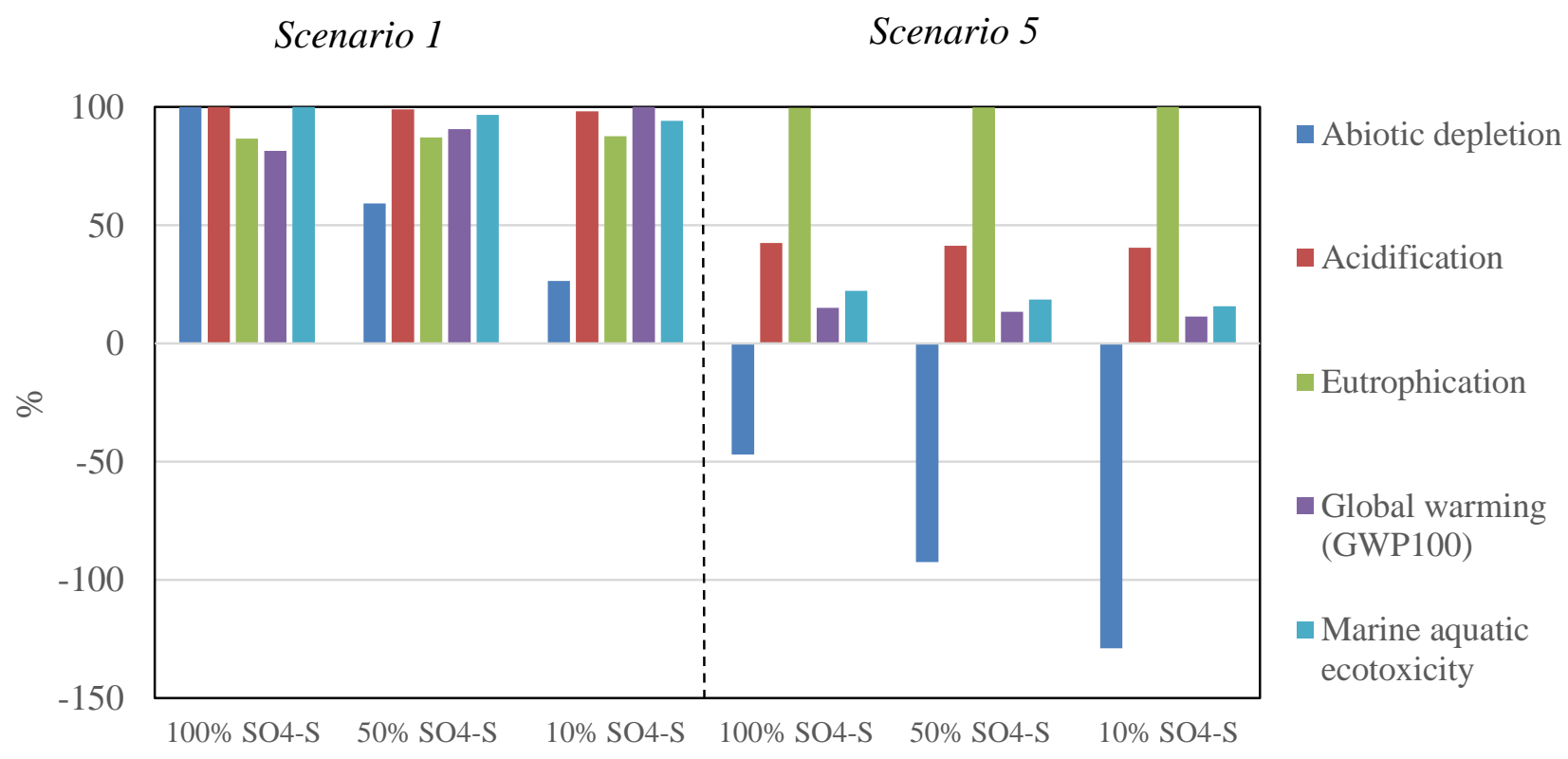

Figure 5. LCA results of Scenarios 1 and 5 in the AnMBR system treating 100, 50 and 10\% of the original sulphate content in the UWW and OFMSW (\% based on normalised values per $\left.\mathrm{m}^{3}\right)$. 